Communication

\title{
Iodized Salt Sales in the United States
}

\author{
Joyce Maalouf 1,2,*, Jessica Barron ${ }^{3}$, Janelle P. Gunn ${ }^{1}$, Keming Yuan ${ }^{1}$, Cria G. Perrine ${ }^{4}$ and \\ Mary E. Cogswell ${ }^{1}$
}

1 Division for Heart Disease and Stroke Prevention, National Center for Chronic Disease Prevention and Health Promotion, Centers for Disease Control and Prevention, Atlanta, GA 30341, USA; E-Mails: JPeralezGunn@cdc.gov (J.P.G.); KYuan@cdc.gov (K.Y.); MCogswell@cdc.gov (M.E.C.)

2 IHRC, Inc., Atlanta, GA 30346, USA

3 Oak Ridge Institute for Science and Education, Oak Ridge, TN 37831, USA;

E-Mail: jessylbarron@gmail.com

4 Division of Nutrition, Physical Activity, and Obesity, National Center for Chronic Disease Prevention and Health Promotion, Centers for Disease Control and Prevention, Atlanta, GA 30341, USA; E-Mail: CPerrine@cdc.gov

* Author to whom correspondence should be addressed; E-Mail: JMaalouf@cdc.gov; Tel.: +1-770-488-8093.

Received: 10 February 2015 / Accepted: 4 March 2015 / Published: 10 March 2015

\begin{abstract}
Iodized salt has been an important source of dietary iodine, a trace element important for regulating human growth, development, and metabolic functions. This analysis identified iodized table salt sales as a percentage of retail salt sales using Nielsen ScanTrack. We identified 1117 salt products, including 701 salt blends and 416 other salt products, 57 of which were iodized. When weighted by sales volume in ounces or per item, $53 \%$ contained iodized salt. These findings may provide a baseline for future monitoring of sales of iodized salt.
\end{abstract}

Keywords: salt; sodium; iodine; sales; United States

\section{Introduction}

Adequate intake of iodine, a trace element, plays a key role in regulating human growth, development, and metabolic functions. It is estimated that, worldwide in 2011, 1.88 billion people were iodine deficient [1,2]. Iodine deficiency can result in goiter, neurocognitive impairment, 
hyperthyroidism, and hypothyroidism [3]. During pregnancy, severe iodine deficiency can cause cretinism, congenital anomalies, and increased neonatal and infant mortality [2], with recent evidence from observational studies suggesting mild to moderate deficiency during pregnancy can lead to reduced IQ and educational achievement among offspring [4,5]. While iodine status is sufficient for most Americans, certain subsets of the population, including pregnant women, may be at risk for mild to moderate iodine deficiency [6-8]. Iodizing salt is a global public health strategy for addressing iodine deficiency [9], yet limited data exist on the proportion of salt that is iodized in the United States.

Historically, iodized salt has been an important source of dietary iodine for Americans; however, not all regular salt is iodized, nor are specialty salts, such as sea salt and kosher salt [10]. Fortification of salt with iodine in the United States is voluntary [11]. A past estimate indicates that approximately $70 \%$ of salt sold to US households is iodized though the method of determining this estimate is unclear [12]. Using Nielsen sales data, this brief provides information on the proportion of iodized and non-iodized table salt sales at the retail level.

\section{Methods}

Nielsen ScanTrack (The Nielsen Co, New York, NY, USA) [13] data from 2009 was used to identify salt products sold in the United States. Nielsen collects information from a stratified probability sample of scanner-equipped chain and large independent grocery stores with estimated total annual sales $\geq \$ 2$ million. Sales data are aggregated and not linked to individuals [13,14]. A total of 1117 salt products were identified using 2 Nielsen grocery modules. Salt products were initially categorized as iodized using the term "IDZD" in the Nielsen product description $(n=67)$. Ingredient and label details were obtained using the manufacturer's and others' websites, following a standard Internet search protocol [15]. Salt products were considered to be iodized if the front of the label or the product name specified it and if iodine was reported on the back in either the nutrition facts panel or the ingredients. Two nutritionists categorized the salt products as iodized or non-iodized and a third resolved any differences.

\section{Results}

In total, 1117 salt products were identified, of which 701 were salt blends (e.g., garlic salt) comprising $16 \%$ of the total sales volume of salt products (Table 1 ). The number of salt products can include more than 1 product from the same brand (e.g., different size containers). Of the remaining 416 salt products, 57 were iodized based on available label information. When weighted by sales volume (in ounces or by each sold), 53\% of salt sold (excluding salt blends) was iodized. Of the $47 \%$ of non-iodized salt sold, about $68 \%$ was regular salt, $19 \%$ kosher salt, and $12 \%$ sea salt. 
Table 1. Proportion of Total Salt Sales by Type of Salt, $2009^{\text {a }}$.

\begin{tabular}{|c|c|c|c|}
\hline Salt Type & $\begin{array}{c}\text { No. in } \\
\text { Sample }^{b}\end{array}$ & $\begin{array}{c}\text { Total Sales } \\
(\%)^{c} \\
\end{array}$ & $\begin{array}{c}\text { Sales Excluding Salt Blends }{ }^{\mathrm{d}} \\
(\%)^{\mathrm{e}}\end{array}$ \\
\hline \multicolumn{4}{|l|}{ Iodized salt } \\
\hline Regular/plain table salt & 35 & 42.2 & 50.1 \\
\hline Salt \& black pepper shaker packet ${ }^{\mathrm{f}}$ & 13 & 1.5 & 1.8 \\
\hline Sea salt & 9 & 1.1 & 1.3 \\
\hline Subtotal & 57 & 44.7 & 53.2 \\
\hline \multicolumn{4}{|l|}{ Non-iodized salt } \\
\hline Regular/plain table salt & 46 & 26.8 & 31.8 \\
\hline Salt \& black pepper shaker packet ${ }^{\mathrm{f}}$ & 22 & 0.04 & 0.1 \\
\hline Sea salt & 14 & 7.6 & 5.5 \\
\hline Kosher salt & 169 & 4.7 & 9.0 \\
\hline Artisan/gourmet/finishing salt & 108 & 0.3 & 0.4 \\
\hline Subtotal & 359 & 39.4 & 46.8 \\
\hline Total (excluding salt blends ${ }^{\mathrm{d}}$ ) & 416 & 84.1 & 100 \\
\hline Salt blends ${ }^{d}$ & 701 & 15.9 & \\
\hline Total (including salt blends) & 1117 & 100 & \\
\hline
\end{tabular}

\section{Discussion}

This analysis identified that only $53 \%$ of table salt sold at the retail level in the United States is iodized. The vast majority of sodium intake is estimated to come from packaged and restaurant foods. It is estimated that only $11 \%-12 \%$ comes from salt added to the table or salt added during home cooking $[16,17]$. To our knowledge, this is the first study to report on the proportion of iodized and non-iodized salt sold at the retail level in the United States. Nielsen ScanTrack data include many products within a given category such as salt. ScanTrack data also include major food retailers in operation across most of the US market. However, sales data from Nielsen ScanTrack do not include warehouse stores (e.g., Walmart and Costco), retailers with sales $<\$ 2$ million, or non-UPC-coded products, and not all places where salt can be purchased were tracked. These findings may provide a baseline for future monitoring of sales of iodized salt in major food retailers in the United States. Tracking the sales of iodized salt over time will help describe potential shifts in the U.S. market share in response to ongoing efforts to reduce salt intake and ensure iodine sufficiency [18,19]. Increasing the proportion of regular salt that is iodized may help improve iodine intakes among pregnant women in the US; however, public health interventions that aim to ensure iodine sufficiency among pregnant and reproductive-age women must also be aware of the potential for excess intake of iodine in other populations [20].

\section{Acknowledgements}

This project was funded by the CDC. There were no external funding sources for this article. 


\section{Authors Contributions}

J. Maalouf assisted in the study design, completed the data abstraction and interpretation, and was the lead author for the article. J. Barron completed the data abstraction and interpretation, and contributed to writing the article. J.P. Gunn assisted in the study design and data interpretation, and provided critical review of drafts of the manuscript. K. Yuan performed the data analysis and reviewed the final draft of the manuscript. C. Perrine assisted in the study design and data interpretation, and provided critical review of drafts of the manuscript. M.E. Cogswell assisted in the study design and data interpretation, and provided critical review of drafts of the manuscript.

\section{Conflicts of Interest}

The authors have no conflicts of interest.

The findings and conclusions in this report are those of the authors and do not necessarily represent the official position of the Centers for Disease Control and Prevention.

\section{Human Participation Protection}

Institutional review board approval was not needed because it did not involve human participants.

\section{References}

1. Andersson, M.; Karumbunathan, V.; Zimmermann, M.B. Global iodine status in 2011 and trends over the past decade. J. Nutr. 2012, 142, 744-750.

2. World Health Organization. Summary Tables and Maps on Iodine Status Worldwide. Available online: http://www.who.int/vmnis/database/iodine/iodine_data_status_summary/en/ (accessed on 28 January 2015).

3. Zimmermann, M.B.; Boelaert, K. Iodine deficiency and thyroid disorders. Lancet Diabetes Endocrinol. 2015, doi:10.1016/S2213-8587(14)70225-6.

4. Bath, S.C.; Steer, C.D.; Golding, J.; Emmett, P.; Rayman, M.P. Effect of inadequate iodine status in UK pregnant women on cognitive outcomes in their children: Results from the Avon Longitudinal Study of Parents and Children (ALSPAC). Lancet 2013, 382, 331-337.

5. Hynes, K.L.; Otahal, P.; Hay, I.; Burgess, J.R. Mild iodine deficiency during pregnancy is associated with reduced educational outcomes in the offspring: 9-year follow-up of the gestational iodine cohort. J. Clin. Endocrinol. Metab. 2013, 98, 1954-1962.

6. Caldwell, K.L.; Makhmudov, A.; Ely, E.; Jones, R.L.; Wang, R.Y. Iodine status of the US population, National Health and Nutrition Examination Survey, 2005-2006 and 2007-2008. Thyroid 2011, 21, 419-427.

7. Caldwell, K.L.; Miller, G.A.; Wang, R.Y.; Jain, R.B.; Jones, R.L. Iodine status of the US population, National Health and Nutrition Examination Survey 2003-2004. Thyroid 2008, 18, 1207-1214.

8. Caldwell, K.L.; Jones, R.; Hollowell, J.G. Urinary iodine concentration: United States National Health and Nutrition Examination Survey 2001-2002. Thyroid 2005, 15, 692-699. 
9. World Health Organization; United Nations Children's Fund; International Council for the Control of Iodine Deficiency Disorders. Assessment of Iodine Deficiency Disorders and Monitoring their Elimination: A Guide for Programme Managers, 3rd ed.; World Health Organization: Geneva, Switzerland, 2007.

10. Dasgupta, P.K.; Liu, Y.; Dyke, J.V. Iodine nutrition: Iodine content of iodized salt in the US. Environ. Sci. Technol. 2008, 42, 1315-1323.

11. US Food and Drug Administration. CFR—Code of Federal Regulations Title 21: Food and Drugs. Sections 184.1634 and 184.1265 2011. Available online: http:/www.accessdata.fda.gov/scripts/ cdrh/cfdocs/cfcfr/CFRSearch.cfm?CFRPart=184 (accessed on 28 January 2015).

12. Salt Institute. Iodized Salt. Available online: http://www.saltinstitute.org/news-articles/iodized-salt/ (accessed on 5 February 2015).

13. The Nielsen Company ScanTrack. Retail Measurement. Available online: http://www.nielsen. com/us/en/solutions/measurement/retail-measurement.html (accessed on 5 March 2015).

14. Ng, S.W.; Popkin, B.M. Monitoring foods and nutrients sold and consumed in the United States: Dynamics and challenges. J. Acad. Nutr. Diet. 2012, 112, 41-45.

15. Gillespie, C.; Maalouf, J.; Yuan, K.; Cogswell, M.; Gunn, J.; Levings, J.; Moshfegh, A.; Merritt, R. Sodium content in major brands of US packaged foods. Am. J. Clin. Nutr. 2015, 101, 344-353.

16. Institute of Medicine. Strategies to Reduce Sodium Intake in the United States; Henney, J.F., Taylor, C.L., Boon, C.S., Eds.; The National Academies Press: Washington, DC, USA, 2010.

17. Mattes, R.D.; Donnelly, D. Relative contributions of dietary sodium sources. J. Am. Coll. Nutr. 1991, 10, 383-393.

18. Webster, J.; Land, M.A.; Christoforou, A.; Eastman, C.J.; Zimmerman, M.; Campbell N.R.; Neal, B.C. Reducing dietary salt intake and preventing iodine deficiency: Towards a common public health agenda. Med. J. Aust. 2014, 201, 507-508.

19. Campbell, N.; Dary, O.; Cappuccio, F.P.; Neufeld, L.M.; Harding, K.B.; Zimmermann, M.B. Collaboration to optimize dietary intakes of salt and iodine: A critical but overlooked public health issue. Bull World Health Organ. 2012, 90, 73-74.

20. Perrine, C.G.; Sullivan, K.M.; Flores, R.; Caldwell, K.L.; Grummer-Strawn, L.M. Intakes of dairy products and dietary supplements are positively associated with iodine status among U.S. children. J. Nutr. 2013, 143, 1155-1160.

(C) 2015 by the authors; licensee MDPI, Basel, Switzerland. This article is an open access article distributed under the terms and conditions of the Creative Commons Attribution license (http://creativecommons.org/licenses/by/4.0/). 